\title{
Hacia una Antropología compartida. Reflexiones, experiencias y propuestas acerca de la fotografía participativa en investigación antropológica ${ }^{1}$
}

\author{
Paula González Granados ${ }^{2}$
}

Recibido: 16 de octubre 2015 / Aceptado: 22 de abril 2016

Resumen. Este artículo tiene dos objetivos principales. En primer lugar, trazar un recorrido por las experiencias colaborativas a través de la fotografía y el video en Antropología, y en segundo lugar, contextualizar y mostrar los resultados de una investigación realizada recientemente sobre proyectos de fotografía participativa impulsados desde colectivos de fotógrafos documentales. Para estos objetivos me he centrado en trabajos pioneros y en autores que han puesto a prueba este tipo de metodologías con niños y adolescentes, escenario de mi trabajo de campo. Esta investigación, que está en sus comienzos, pretende buscar sinergias con otros profesionales y poder así establecer teorías y colaboraciones de cara a próximos proyectos de investigación aplicada a través del uso de los medios audiovisuales.

Palabras clave: fotografía; Antropología compartida; multidisciplinariedad; etnografía.

\section{[en] Towards a shared anthropology. Reflections, experiences and proposals on participatory photography in anthropological research}

\begin{abstract}
This article has two main objectives. Firstly, to portray the diverse collaborative photography and video experiences in Anthropology. Secondly, to contextualize and share the results of recent research on participatory photography projects promoted by documentary photography collectivities. To this end, I have focused on pioneering works and authors who have tested these methodologies with children and adolescents who are the subject of my fieldwork. This research, which is at a commencing stage, aims to establish synergies with other professionals and therefore establish theories and collaborations in regards to future applied research projects through the use of audiovisual media. Keywords: photography; shared Anthropology; multidisciplinary; ethnography.

Sumario. 1. Introducción. 2. Hacia una Antropología compartida. Pioneros y referentes. 3. Apuntes sobre el trabajo de colectivos de fotógrafos documentales y las sinergias con los proyectos de investigación antropológica. 3.1. Contextualización: colectivos y proyectos analizados. 3.1.1. Ruido Photo. 3.1.2. Las Cientovolando. 3.1.3. Photographic Social Vision. 3.1.4. Piel de Foto. 3.2. Recapitulación de las principales conclusiones extraídas de la investigación 3.3. Propuesta de integración de la investigación social en proyectos de fotografía participativa. 4. Referencias bibliográficas.
\end{abstract}

Como citar: González Granados, P. (2016). Hacia una Antropología compartida. Reflexiones, experiencias y propuestas acerca de la fotografía participativa en investigación antropológica, en Revista de Antropología Social 25(1), 61-84.

\footnotetext{
1 Parte de este artículo versa sobre una Investigación financiada por el Departamento de Cultura de la Generalitat de Cataluña.

2 Universidad de Zaragoza

pgg@unizar.es
} 


\section{Introducción}

En Antropología, las ideas positivistas de la imagen como prueba fehaciente de una realidad se confrontan desde hace décadas con las voces que demandan un uso de la imagen fotográfica como espacio de diálogo, que deja las puertas abiertas para diferentes análisis y narrativas, que se contraponen unas a otras dando lugar a constantes cambios en las maneras de mirar esas imágenes. Estas cuestiones tienen que ver con los cambios en la forma de entender la alteridad, con las fronteras borrosas entre metodologías y las profesiones que las utilizan, con la capacidad de generar conocimientos diferentes y desde distintas perspectivas. Por ello, al tratar de acercarnos a los procesos participativos y colaborativos, tenemos que tener en cuenta que hablamos de una evolución general del conocimiento antropológico y del uso de los medios audiovisuales en la disciplina.

Este artículo va a tener una doble orientación. En primer lugar teórica, ya que echaré la vista atrás y trataré de aquellos proyectos que desde la Antropología han buscado utilizar los medios audiovisuales en sus investigaciones, bien sea porque sus autores creen que es la única manera de "retratar" a las personas y colectividades que investigan, o bien porque se busca denunciar y hacer más visible las situaciones de exclusión por las que pasan las personas y los colectivos investigados. Me centraré en proyectos que han inspirado mi propio trabajo, en los cuales se ha entendido el medio audiovisual como una herramienta que acerca posiciones entre investigador e investigados, que facilita una investigación compartida y comprometida con todas las partes implicadas ${ }^{3}$.

En segundo lugar, y con una orientación etnográfica, dedicaré un capítulo a una investigación finalizada a principios del año 2015 sobre colectivos de fotógrafos que utilizan la fotografía participativa en todos o algunos de sus proyectos. El interés que siempre he tenido en estos colectivos tiene que ver con la búsqueda de sinergias entre diferentes ámbitos profesionales, ya que trabajan con fenómenos sociales y personas con las que también trabajamos las profesionales del ámbito de la Antropología. Mi intención es continuar con esta investigación e ir así tejiendo una red de profesionales interesados en utilizar la fotografía de manera colaborativa en proyectos de investigación-acción participativa ${ }^{4}$.

Los objetivos principales que subyacen a este trabajo son, por una parte, realizar un mapeo de los proyectos que se realizan desde el ámbito de la fotografía profesional en torno a la fotografía participativa y, por otro, aunar estas experiencias con la mía propia en el ámbito de la Antropología Audiovisual y más concretamente en el de la investigación-acción participativa.

Finalmente, en el trasfondo de este trabajo subyace una reflexión sobre el futuro de la disciplina Antropológica y las posibilidades de fomentar una "Antropología de la Orientación Pública [...], relacionada con una visión problematizadora de la 'an-

3 No trataré en este artículo las cuestiones puramente metodológicas ya que éstas no forman parte de los objetivos del mismo. Para este tipo de cuestiones véase: González, (2011a, 2011b, 2014), Packard (2008), Pink (2001).

$4 \quad$ En este artículo no profundizaremos en la definición y bases estructurales de la Investigación-Acción Participativa (IAP). A pesar de ello decir que comparto las ideas de uno de los pioneros de esta epistemología como es Fals Borda: "Recordemos que la IAP, a la vez que hace hincapié en una rigurosa búsqueda de conocimientos, es un proceso abierto de vida y de trabajo, una vivencia, una progresiva evolución hacia una transformación total y estructural de la sociedad y de la cultura con objetivos sucesivos y parcialmente coincidentes (Rahman y Fals Borda, 1989: 213). 
tropología' que busca mostrar y desarrollar su capacidad para enfrentarse de manera eficaz a la comprensión de los problemas sociales del mundo contemporáneo [...] iluminando tales problemáticas y contribuyendo a su discusión pública" (Gimeno, 2008: 247), y que "reflexiona y participa activamente en las transformaciones sociales" (Robles, 2012: 149). En definitiva, se aboga por que la Antropología ocupe un puesto significativo en espacios de intervención social a través de las bases teóricas, metodológicas y éticas que rigen nuestra práctica. Este objetivo es fundamental para que los profesionales de la Antropología podamos mostrar las potencialidades que tiene nuestra disciplina más allá del ámbito universitario.

\section{Hacia una Antropología compartida. Pioneros y referentes}

Comenzaré esta reflexión teórica con el trabajo de Jean Rouch, que no utilizó la fotografía sino el medio fílmico, pero que es pionero, y uno de los mayores ejemplos, de una manera diferente de aproximarse desde la Antropología a un grupo de personas a través del medio audiovisual.

Rouch rechaza frontalmente las concepciones positivistas del medio fílmico, que dan por hecho que todo aquello recogido de esta manera se convierte automáticamente en documento, asegurando que aquello que vemos es la realidad, aunque haya estado obviamente manipulada por una persona con un bagaje cultural concreto. El director dirá que esta corriente está profundamente marcada por un sentido de dominación y superioridad por parte de los investigadores hacia los investigados, denominados como "objeto de estudio". El antropólogo rechazará esta manera de hacer y se dirigirá hacia lo que ha llamado antropología compartida — shared anthropology—.

The observer is finally coming down from his ivory tower; his camera, his tape recorder, and his projector have led him — by way of a strange initiation path - to the very heart of knowledge and, for the first time, his work is not being judge by a thesis committee but by the very people he came to observe (Rouch, 1974: 96).

Son muy numerosos los ejemplos fílmicos en los que Rouch explicita esta manera de proceder, pero me quedaré con el de la Pyramide Humaine (1959), ya que ha sido una de las películas de este investigador que más me ha inspirado en mi propio trabajo. Al principio de la película escuchamos su voz que habla, en primera persona de la población juvenil en Abiyán, capital de Costa de Marfil en aquel momento, y la relación que se establece entre alumnos blancos y negros en las clases. El director escoge un grupo de 20 alumnos de primero de bachillerato y les propone hacer una película en que se muestre el racismo existente y la difícil relación entre alumnos europeos y africanos. En esta película cada uno ejercerá un papel, desde los permisivos con este tipo de relaciones hasta los que se muestran totalmente contrarios. Primero aparece Rouch ante la cámara con los alumnos europeos y les explica su idea, tras lo que ellos expresan sus inquietudes, sobre todo en lo que tiene que ver con su capacidad para poder llevar a cabo el experimento. Después aparece su reunión con el grupo de jóvenes africanos, que también expresan alguna inquietud, pero que acaban aceptando el reto. Tal como dirá desde el comienzo de la película: "en lugar de reflejar la realidad, esta película crea otra realidad [...] la improvisación constante es la única regla" (Rouch, 1959). Con esto hace alusión a lo que denominó etnoficción, 
que es la búsqueda de una realidad que surge a partir de esta improvisación, y que está en manos de los propios protagonistas de la película, que decidirán cómo representarse en todo momento. Vemos cómo se va desarrollando una historia, un drama, que pasa por diferentes fases: desde el debate entre un grupo y otro, donde vemos las diferentes posiciones que rechazan o alientan la mezcla, hasta la realización de este encuentro y las consecuencias del mismo, que desenlazan en un final dramático. El objetivo de Rouch tiene que ver con crear una reflexión tanto en los propios protagonistas del filme como en el público que lo vea, dejando lugar a un espacio creativo de intercambio que será el que permita que los hechos se desarrollen y lleven a una reflexión final sobre el tema.

Esta transgresión de Rouch — este paso de las fronteras que deja lugar a la creatividad y a que los protagonistas de la película tengan iniciativa a la hora de representarse- es lo que se incluyó en la corriente francesa del 'cinema-verité'. En el caso de Rouch es "una etnografía de las narrativas culturales y el testimonio de un encuentro particular, explicado mediante la imprimación declaradamente subjetiva de la intervención del autor" (Grau, 2005: 5).

El verdadero compromiso de Rouch está en sentar las bases de un cine comprometido - cine-sinceridad-, en el que no es tan importante la forma como el contenido. Un cine que ha de ser aceptado por las personas representadas, las cuales participan en el proyecto y se ponen de acuerdo para poder llevarlo a cabo. La presencia del director-antropólogo es también evidente en todas las etapas, y no pretende esconderse tras una realidad pretendidamente objetiva, sino que muestra su intervención, su posición, los sentimientos que le mueven a realizar la película. Para Rouch, "Film is the only method I have to show another just as I have seen him" (Rouch, 1974: 95). La reflexión con la que nos quedamos tiene que ver con las preguntas que el investigador debe hacerse desde los comienzos de una investigación, y que están relacionadas con cuestionarse para quién hacemos una película y para qué; porqué y para quién ponemos la cámara entre un grupo de personas (Rouch, 1974: 94).

Aunque con contenidos y finalidades muy diferentes a los de Rouch, es inevitable en este recorrido hacer alusión al trabajo de Sol Worth y John Adair con un grupo de indios Navajo en Arizona. El trabajo en el que mostraron sus investigaciones, Through Navajo Eyes (1972), se centra en analizar cómo un grupo social homogéneo construye la técnica cinematográfica a partir de la transferencia de los medios necesarios para ponerla en práctica, entendiéndola como un constructo socialmente elaborado. Según sus hipótesis, poner la cámara cinematográfica en manos de los informantes y mostrarles los rudimentos de su uso supone la captación de su propia visión de su mundo lejos de un punto de vista ajeno, que sería lo que obtendríamos si la cámara estuviera en manos de los investigadores:

If a member of the culture being studied could be trained to use the medium so that with his hand on the camera and editing equipment he could choose what interested him, we would come closer to capturing his vision of his world (Worth y Adair, 1972: 14 ; las negritas son de los autores).

Al fin y al cabo, nos dirán, el lenguaje visual a través de la cámara se aprende, y lo que ellos pretenden es analizar cómo, una vez aprendido este lenguaje, los Navajo lo utilizan, al igual que podría hacerse con el análisis de cualquier sistema de comunicación simbólico, como el lenguaje, la música, el arte, etc. Por ello, engloban esta 
investigación dentro de los "estudios de la comunicación" y su principal finalidad es analizar las imágenes que toman los Navajo para determinar cómo ven a través de la cámara de vídeo.

El problema principal del trabajo de estos autores estriba en que los investigadores enseñan a los informantes una manera determinada de comunicar (Worth y Adair, 1972: 254), pero en ningún momento explicitan que esto pueda suponer un sesgo para la investigación, que llegará a mostrar lo que efectivamente ellos quieren evitar: una visión de los Navajo pero a través de los ojos de los investigadores. Es aquí donde este trabajo pionero recibió sus máximas críticas, en eludir los sesgos que la presencia del investigador crea además de la inclusión de un instrumento ajeno a la comunidad, como es la cámara de vídeo, que ha sido introducido directamente en el campo sin que se haya dado un trabajo previo que mida las consecuencias de este hecho. Los autores muestran una postura pretendidamente objetiva cuando está claro que su presencia causó una serie de dinámicas en el terreno que les incluyen a ellos mismos, teniendo sobre todo en cuenta que estaban poniendo en manos de las personas un objeto que tiene un valor simbólico, y que por ello crea desigualdades cuando se plantea este tipo de proyectos. De esta manera, el objetivo de los autores de mostrar "la forma de mirar de los Navajo" queda incompleto en el momento en que sus explicaciones eluden tratar sobre la presencia del investigador y la cámara de video en el campo, cuando pretenden obtener unas conclusiones científicas de un proceso que no se ha hecho explícito.

Otro trabajo a destacar fue el del realizador Timothy Asch entre los indios Yanomamo de Venezuela. Este director colaboró en sus producciones con antropólogos y señaló la importancia de la relación realizador-investigador para establecer criterios negociados (Asch, 1995). La idea principal que desarrolla Asch es generar tanto productos audiovisuales como teóricos en un trabajo común, y así poder profundizar mucho más en los temas tratados. La película más conocida de Asch, realizada junto al antropólogo Napoleón Chagnon fue A man called Bee (1974), en la que Chagnon aparece como principal protagonista y hace una descripción del pueblo Yanomamo. Esta aparición del antropólogo como uno más en el producto documental es un hito, ya que hasta el momento se pretendía mantener la objetividad del documento audiovisual "escondiendo" la presencia del investigador.

Un proyecto de gran relevancia en la transferencia de medios audiovisuales a la población se desarrolló a partir de los años 90 desde el Instituto Nacional Indigenista en México para formar a las comunidades indígenas en el uso de estos medios. De 1990 a 1994, un grupo de cineastas y antropólogos realizaron el proyecto de capacitación y donación de equipos de video a comunidades y organizaciones indígenas de todo el país. En 1994 se creó el primer Centro de Vídeo Indígena de Oaxaca. La propuesta inicial de este ambicioso proyecto fue:

La capacitación en la técnica del vídeo, asesorías para la realización de proyectos, préstamo de equipos, servicios de edición y postproducción y difusión del vídeo indígena por medio de su videoteca, proyecciones en comunidades, organización de muestras y participación en festivales nacionales e internacionales (Bayona, 2001).

Bayona (2001) investiga también de otros proyectos centrados en el medio fotográfico, como el de las camaristas Sbeik, en el cual un grupo de mujeres de San Cristóbal de las Casas (México) aprenden en talleres a utilizar las cámaras fotográ- 
ficas y desarrollan proyectos personales sobre temas que escogen tras un proceso de negociación y reflexión constante con los coordinadores de estos proyectos.

En relación al medio fotográfico, el trabajo antropológico que más influencia ha tenido en posteriores experiencias en la fotografía participativa es el de Wang, Burris y Yue Ping (1996) y su técnica denominada como "fotonovela" (photo novella). Su trabajo está basado en la intervención con mujeres que viven en el ámbito rural chino, en la provincia de Yunnan. Uno de los objetivos de este proyecto fue crear un material fotográfico realizado por estas mujeres para que pudiera mostrar otra realidad a los políticos de la zona, y fueran así conscientes de sus dificultades a la hora de conjugar el trabajo y la atención sanitaria de la familia. Los otros objetivos tenían que ver por una parte, con empoderar a estas mujeres para que registraran estos aspectos de sus vidas, y por otra, aumentar su conocimiento acerca del estatus de la salud de las mujeres en su zona. Estos tres objetivos son entendidos por las autoras como educativos, ya que se trata de transmitir un conocimiento - el uso de la fotografía documental - y a partir del mismo producir cambios en sus maneras de pensar y entender las problemáticas que viven. La base de la que parten es que no hay nadie más adecuado que las propias mujeres para llevar a cabo este trabajo, ya que son ellas quienes sufren las injusticias propias de su condición de mujeres y madres trabajadoras.

Tal como dirán las autoras:

In photo novella, Chinese village women are visual anthropologists. They use photography to record images to which outsiders are much less likely to have access. They are lay anthropologists as well. They acquired their skill at observation not from formal schooling in the social sciences, but from watching "the crops grow, the seasons change, the animals being born and slaughtered." They are also natural anthropologists. They draw on their existing relationships to serve the communities of which they will forever be a part (Wang, Burris y Yue Ping, 1996: 1399).

Estas autoras enmarcan su trabajo desde teorías feministas, ya que buscan dar a las mujeres el poder sobre su propia representación para que se muestren como ellas quieran, y no a través de los ojos de académicos o políticos (normalmente masculinos), los cuales pueden mostrar una imagen distorsionada y alejada de la realidad. También basan su intervención, entre otras, en la filosofía de Freire: "In Freirian terms, one medium that can be used to reflect the community back upon itself, and to reveal the everyday social and political realities that influence people's lives, is photography." (Wang, Burris y Yue Ping, 1996: 1392).

Otra reflexión interesante en este sentido es la que Bettina Kolb (2008) realiza sobre la entrevista participativa en torno a fotografías tomadas por los informantes, dentro de un proyecto de investigación en pueblos de seis provincias de China y cinco comunidades islámicas del Mediterráneo, que tiene que ver con aspectos de organización social y participación colectiva. La idea de que los participantes se convierten en investigadores aparece de nuevo. Un aspecto al que apela la autora es la capacidad transcultural de los informantes de tomar e interpretar imágenes, lo que hace que el trabajo con fotografías pueda realizarse en cualquier contexto: "Respondents in cultural settings as diverse as Vienna, Damascus, Cairo and China have been able to use their cultural knowledge to code - in taking photos - and decode — narratively in the interview_ visual images during the photo interview." (Kolb, 2008). 
La vertiente aplicada de estas tres investigaciones es obvia, y podríamos decir que es la más importante, ya que como hemos dicho, uno de los mayores objetivos en ellas es crear este material para llegar a lograr metas que mejoren la calidad de vida de la comunidad. Esta aplicación de la Antropología, tal como dice San Román (2006), se ha minusvalorado enormemente, lo que desemboca, entre otras cosas, en la invisibilidad de nuestra profesión y el consecuente desconocimiento acerca de las tareas que los profesionales de la Antropología podemos llevar a cabo. En Antropología, tal como dice la autora,

Trabajamos para fundamentar teóricamente y apoyar en la práctica el mutuo entendimiento, la equidad del diálogo, la búsqueda de alternativas adecuadas y el estímulo de la negociación de los objetivos y de los medios adecuados para lograrlos (San Román, 2006: 397).

Conocimiento y aplicación, teoría y práctica, no tienen por qué estar desvinculados o ser opuestos. Los conocimientos que adquirimos durante la etnografía son, o deben ser, aplicables de algún modo que pueda ser efectivo en el terreno que trabajamos, lo que no implica que nuestros trabajos sean menos científicos, o menos académicos, sino todo lo contrario. Señaló además, que debería ser una premisa ineludible el hecho de que esos conocimientos se obtengan a partir de la negociación de los objetivos en base a las necesidades de la comunidad, porque de otra manera se desdibujan las intencionalidades y la aplicabilidad de las investigaciones sociales.

Otro aspecto que trata San Román es la autonomía de las personas con que trabajamos, lo cual ha de potenciarse para que puedan participar de manera activa en el proceso etnográfico. En muchas ocasiones esta autonomía se ve comprometida por el hecho de encontrarse estas poblaciones en situación de desigualdad y de falta de recursos que provocan una clara limitación a la hora de tomar decisiones. Se trata, entonces, de que el proceso etnográfico las considere como personas autónomas, que pueden crear y generar conocimiento en colaboración con el antropólogo, el cual tiene como responsabilidad crear ese espacio donde poder desarrollar la participación y el consenso sobre los temas que les afectan. Los medios audiovisuales, la fotografía en particular, pueden aportar una nueva herramienta que dé autonomía y empodere a estas poblaciones. Tal como expresan Wang, Burris y Yue Ping: "the visual image is a communication tool that can educate, inspire and influence decisions." (Wang, Burris, Yue Ping, 1996: 1392).

Un colectivo con el que se ha trabajado profusamente en busca de esta autonomía es el de los niños y jóvenes, referido en algunos artículos como "giving-kidscameras". Una razón para especializar la práctica en este colectivo es que tradicionalmente se les ha considerado como personas en transición hacia la vida adulta, lo que niega cualquier validez a sus aportaciones y silencia en muchos casos lo que puedan decir acerca de cuestiones que afectan a su vida y la de su comunidad. Existen estudios como por ejemplo el de Sharples, Davison, Thomas y Rudman (2003), realizada con personas pertenecientes a tres niveles de edad ( 7,11 y 15 años) en cinco países europeos. Estos autores afirman ante cualquier duda sobre su concepción de las imágenes producidas en este tipo de proyectos: "Children's photographs are not just their 'view of the world', but are also a construction of their identity in relation to their parents and peers." (Sharples, Davison, Thomas y Rudman, 2003: 324). Lo que tratan es analizar las fotografías que toman los participantes no como 
productos finales, sino como resultados de un proceso en el que se incluyen tanto los investigadores como las personas que les rodean y que, aunque no aprieten el botón, están presentes de alguna manera en el producto final. Esto es válido para todo tipo de material audiovisual, que debe ser analizado no como prueba de una realidad, sino como construcción cultural que ha sido mediada por diferentes actores e ideologías.

Estos proyectos se centran en analizar la producción fotográfica de colectivos infantiles concretos, ya sean los niños trabajadores de Inglaterra (Mizen, 2005), los niños inmigrantes de una escuela en un barrio obrero (Lutter, 2010) o los niños de la calle en Accra - Ghana- (Mizen y Ofosu-Kusi, 2010), entre otros. Como vemos, son proyectos que trabajan con colectivos excluidos y que buscan entrar en mundos en principio inaccesibles a través de la cámara de fotos, que ellos mismos introducen en el campo y distribuyen entre los participantes. Los investigadores aseguran no dar directrices a los niños más allá de los conocimientos básicos de la cámara, argumentando que quieren mediar lo mínimo con su mirada adulta en la práctica fotográfica que realicen. Basándome en mi propio trabajo de campo ${ }^{5}$ opino que esta afirmación es arriesgada ya que, aunque los niños tomen las fotografías como quieran, siempre se ha de tener en cuenta que su propia presencia en el campo ya está mediando en sus imágenes puesto que lo hacen teniendo en cuenta una audiencia determinada. Es necesario detenerse en este hecho para no caer en el error de ver los materiales obtenidos como datos puros, documentales, que los participantes habrían tomado de igual manera aunque los investigadores no hubieran entrado en sus vidas. Se ha de problematizar el uso de la fotografía al igual que se hace con otras técnicas, porque de otra manera es fácil recibir críticas sobre la falta de profundidad teórica o la "inocencia" con respecto al uso de la cámara fotográfica.

En estos trabajos se asegura que la fotografía tomada por los propios participantes elicita una información que tampoco obtendríamos por medio de otro tipo de técnicas, como la entrevista tradicional. Lutter, en su trabajo con niños y niñas migrantes en una escuela de Inglaterra, enumera sus razones para utilizar estas técnicas:

Because it is a means to both rouse and reframe conversations (a) among the children themselves (b) between the children and participant adults (researchers, teachers, and parents) (c) among viewers/ readers (specifically educators) about children's own understandings and experiences of childhood (Lutter, 2010: 225).

Todas estas audiencias que pueden tener acceso a estas fotografías y algo que decir sobre ellas han de ser tenidas en cuenta al analizar las imágenes producidas, lo que supone un ejercicio de reflexividad y transparencia que, como hemos visto, Rouch reivindicaba para todo tipo de investigaciones. Debemos asumir que nuestra presencia como adultos, investigadores, académicos, y profesores exige una constante auto-reflexión acerca de nuestra posición en el campo, lo que nos ayudará a establecer relaciones de confianza con los participantes, ya que desde un principio conocen los objetivos y la razón de nuestra presencia entre ellos. Esta reflexividad permitirá que se cree un clima de trabajo favorable para la improvisación y la libertad de los participantes para tomar las fotos que quieran, de la manera que quieran.

Quisiera detenerme en este hecho pues he echado en falta en estas investigaciones una reflexión explícita sobre los sesgos que supone un proyecto de este tipo, y 
las estrategias para limarlos en la medida de lo posible. Esta reflexividad es imprescindible en cualquier tipo de investigación, y especialmente en aquellas en las que se introduce un elemento como la cámara fotográfica y se pide la participación de un colectivo para obtener imágenes de sus vidas. También es importante hacer alusión al proceso que conlleva la toma de confianza con los participantes y a las estrategias que se aplican para establecer una buena relación con poblaciones infantiles y juveniles. Tal como describía en mi tesis doctoral:

Mi rol como adulta y posible sancionadora sesgaba evidentemente la información que los participantes pudieran darme, por lo que tuve siempre en cuenta este hecho. Repetir en cada entrevista la promesa de la confidencialidad era imprescindible con ellos, ya que me daba cierto margen para que entendieran que no estaba allí para sancionar, sino para recoger información (González, 2011a: 293).

La investigación en ámbito educativo con niños y adolescentes ha de ir acompañada de una estancia prolongada en el campo que facilite el establecimiento de relaciones de confianza con los participantes ${ }^{6}$. Esta estancia de campo permitirá, por una parte, conocer sus rutinas y que aprendamos a movernos en su entorno y, por otra, que se sientan implicados en el proyecto, ya que en cada encuentro se proponen actividades en las que se fomenta su participación en la toma de decisiones y en el desarrollo del mismo. En el caso de los talleres que llevo a cabo ${ }^{7}$ destacaría la actividad denominada paseos fotográficos, que consiste en realizar trayectos por su ámbito urbano de referencia, consensuando con el grupo qué lugares ir a fotografiar y analizando durante los mismos la praxis fotográfica implícita a las dinámicas que allí se generan. Esta es, además, una actividad que potencia la participación, pues son los informantes quienes deciden donde ir y qué fotografiar, con la presencia de la antropóloga como observadora del "juego" fotográfico. Estas actividades cumplen entonces una doble función; por una parte, permiten observar la praxis fotográfica dentro del grupo y conocer el entorno en que viven y por otra se potencian dinámicas atractivas para los participantes, pues suponen una ruptura de sus rutinas y un empoderamiento al decidir qué lugares enseñarán a la investigadora. Este hecho permite establecer relaciones de confianza, limar los sesgos propios de una investigación de este tipo y tender puentes de comunicación investigador-informantes.

Por último, quisiera destacar que todas las investigaciones nombradas hasta este momento trabajan a partir del potencial evocador y potenciador de diálogo de la representación fotográfica, que supone un puente de comunicación a través del cual trabajar sobre lo que piensa la gente, centrándose sobre todo en temas de autorepresentación y de narración de la vida cotidiana. No hay que olvidar que la fotografía, desde su nacimiento, se ha desarrollado espectacularmente hasta hacerse un hueco en todos los rincones del mundo, suponiendo de esta manera un elemento que va más allá de las fronteras físicas o simbólicas y que facilita el diálogo transcultural. Tal como apunta Edwards:

6 Esta afirmación puede aplicarse a cualquier proyecto de investigación social, en este caso se destaca en el trabajo con niños y adolescentes pues es en el que se ha desarrollado principalmente el trabajo de la autora. Talleres sobre los cuales puede obtenerse toda la información en la tesis doctoral de la autora (González, 2011b) 
Photography can communicate about culture, people's lives, experiences and beliefs, not at the level of surface description but as visual metaphor which bridges that space between the visible and invisible, which communicates not through the realist paradigm but through a lyrical expressiveness (1999: 58).

Esta expresividad del medio fotográfico justifica su presencia en los proyectos de investigación social y, por qué no, en proyectos interdisciplinares y de intervención social que entiendan el uso de estos medios no únicamente como maneras de llegar a responder una pregunta de estudio, sino también como generadores de procesos que van dirigidos a producir cambios y que se desarrollan en colaboración con las personas, y no para o acerca de ellas.

\section{Apuntes sobre el trabajo de colectivos de fotógrafos documentales y las sinergias con los proyectos de investigación antropológica}

A continuación expondré aquellos puntos más significativos de una investigación en la que entrevisté a los coordinadores de proyectos de fotografía participativa en España, y a algunos de los participantes de los talleres realizados. Existen muchas más experiencias alrededor del mundo, pero yo me centré en estos cuatro colectivos: Ruido Photo, Las Cientovolando, Photographic Social Vision y Piel de Foto. De estos cuatro proyectos, tres de ellos están afincados en Cataluña. Más que una explicación basada en la territorialidad — derivada de la fuente principal en financiación de esta investigación (el Departamento de Cultura de la Generalitat de Cataluña)-, los proyectos fueron seleccionados bien por su largo recorrido en el ámbito de la fotografía participativa en España o por la profundidad de su trabajo y compromiso con los proyectos abordados.

Una de las intenciones más claras a la hora de acercarme a estos proyectos es buscar sinergias con otros profesionales y encontrar así diferentes maneras de llevar a cabo proyectos de investigación acción social participativa, en este caso centrados en el uso de la fotografía como herramienta elicitadora y potenciadora de cambios en las personas con las que trabajamos.

En primer lugar contextualizaré cada uno de estos colectivos, centrándome sobre todo en los proyectos de fotografía participativa que han realizado, para luego pasar a desarrollar los puntos más importantes que obtuve de las entrevistas realizadas.

\subsection{Contextualización: colectivos y proyectos analizados}

\subsubsection{Ruido Photo}

Ruido Photo $^{8}$ es una organización integrada por fotógrafos, periodistas y diseñadores, que entiende el documentalismo como una herramienta de reflexión y transformación social. Es una plataforma desde donde ejercer un documentalismo independiente, con fuerte contenido social y compromiso cultural. Trabaja en áreas temáticas definidas: migración, conflictos y violencia. Desde 2004, idean proyectos que contribuyen a fomentar la participación, el debate y la sensibilización sobre

8 http://www.ruidophoto.com/ (consultado: 6 de abril de 2016). 
temas relacionados con los derechos humanos. Buscan formas de producción y realización innovadoras. Trabajan en diferentes formatos, como fotografía, texto, video o multimedia, que transforman en libros, largometrajes, exposiciones, dinamización comunitaria, blogs.

Los proyectos de fotografía participativa sobre los que pude tratar con dos de los fundadores de este colectivo, Pau Coll y Anna Bosch ${ }^{9}$, son los siguientes:

- Cruzando miradas. Mujeres y espacio público en el Rabal (2006). En este proyecto participó Anna Bosch y fue su primera experiencia en este ámbito. En él participaron mujeres de diferente procedencia y edad que vivían en el barrio del Rabal y se hizo una exposición final en un parque degradado del barrio.

- Mira'm bé (2006-2007). A raíz del anterior proyecto, se estableció contacto con el Ayuntamiento de Granollers y a través de un plan de mejora se pudo desarrollar un proyecto de fotografía participativa con jóvenes en el barrio del Congost. Tuvo un año de duración y la entrevistada recuerda la experiencia como muy positiva, a pesar de las dificultades que conllevan este tipo de proyectos (pérdida de cámaras, ausencia de los participantes...).

- Herencia Ciega. Foto participativa desde el exilio (2009). Proyecto de un mes de duración realizado con un grupo de 10 niños que viven en el Sahara con edades entre los 9 y los 11 años. Éste es un ejemplo de proyecto de corta duración, lo que según Pau Coll conlleva dos aspectos a tener muy en cuenta: el primero, que se debe conocer el terreno al que se va, para no condenar el proyecto al fracaso. El segundo, que el proceso en un proyecto de este tipo ha de ser mucho más práctico desde el principio, para contar con tiempo suficiente para tratar uno o dos temas consensuados con el grupo a partir del análisis de las imágenes.

- FotoDentro. Imagen y población reclusa (2007-2009). Proyecto realizado en colaboración con TeatroDentro en la cárcel de Quatre Camins. Aquí tenemos un ejemplo de proyecto de larga duración, llevado a cabo sin apenas financiación y con una implicación importante por parte del colectivo y los participantes. Tal como comentaba Pau Coll, la relación de Ruido Photo con el mundo de la cárcel es estrecha, y sus objetivos tienen que ver con visibilizar la vida de los presos y con facilitar que realicen una actividad que les permita expresarse. Según se lee en su página web: "Trabajar sobre las imágenes con población reclusa para nosotros significa intentar minimizar el daño que la privación de libertad produce en el individuo, desarrollar un proceso formativo informal y favorecer la creación de un canal de comunicación entre la prisión y el mundo de fuera" (http://www.ruidophoto.com/photo/?p=1173. Consultado: 6 abril 2016)

- Cuidado que muerden. Taller de fotografía comunitaria en torno al movimiento rockero en Cuba (2010-2011). Josu Trueba junto con Pau Coll fueron los coordinadores del proyecto. Antes de comenzar este proyecto Trueba ya había estado durante meses en Cuba realizando su propio proyecto de fotografía

9 Hay que decir que actualmente Anna Bosh trabaja y es fundadora de un centro de formación en fotografía, Centre de Fotografia Documental i Mitjans Audiovisuals de Barcelona, y que no colabora activamente en los proyectos de Ruido Photo desde 2010. 
documental sobre los punks en Cuba. Al volver la segunda vez a Barcelona, y sabiendo que tenía un material potente y personas muy interesadas en trabajar con la foto, habla con Pau Coll, y juntos vuelven con cámaras fotográficas para dinamizar los talleres. Tanto la exposición final como los talleres se llevaron a cabo en La Habana, en una galería de arte de la Habana vieja. Pau Coll y Josu Trueba coinciden en que este proyecto supone una ruptura de los estereotipos que tienen la población en general sobre Cuba, y también una manera de que los punks se den también a conocer en su propia ciudad, donde son apartados. Josu Trueba también insiste en la calidad de las imágenes, que achaca a la formación artística que tienen los cubanos, lo que hace más fácil la comprensión del lenguaje visual.

- Aula de Creación Visual. Taller de fotografía participativa en el Centro Penitenciario de Jóvenes de Cataluña (2011-2012). Este proyecto fue llevado a cabo por Pau Coll, Mireia Bordonada y Lara Garroum. El grupo de participantes más estable estuvo formado por ocho personas, que permanecieron en el proyecto durante los 7 meses que duró. Es un proyecto de larga duración, en el que se dio el tiempo suficiente para trabajar a fondo aspectos técnicos y de lenguaje visual. Pude entrevistar a Albert, uno de los participantes de estos talleres, y él me transmitió el entusiasmo con el que vivieron este proceso dentro de la cárcel, que además les permitió hacer cosas que nunca hubieran imaginado: hacer fotos fuera de las aulas para talleres, meter una cámara en su celda y grabarse, conseguir transmitir emociones y sentimientos a través de la foto.

- Identitats. Taller de fotografía participativa con las residentes de "El Recés", Ciutat Vella, Barcelona. Durante tres meses las jóvenes que conviven en este servicio de acogida temporal aprendieron lenguaje visual para poder contar su realidad a través de la fotografía, mostrar su entorno más cotidiano y dar su propia visión de su identidad. Ellas mismas también documentaron todo el proceso del proyecto en un cortometraje de video documental. Todo ello para realizar una muestra expositiva colectiva con más de 100 fotos que se pudo mostrar en el propio centro de acogida donde ellas viven.

\subsubsection{Las Cientovolando}

Este colectivo nace en el año 2012 y está formado por dos fotógrafas, Almudena Caso y Eva Sala. Ambas llevan desde el 2006 involucradas en proyectos de fotografía participativa, con colectivos muy diversos ${ }^{10}$. Las Cientovolando se describen a sí mismas de la siguiente manera:

Almudena Caso y Eva Sala somos dos pájaras (RAE: mujeres astutas, sagaces y cautelosas) fotógrafas de formación con experiencia en proyectos participativos y sociales principalmente audiovisuales. Hemos nacido en Madrid entre 1974 y 1982 [...] Vo-

10 Han trabajado de manera individual en proyectos con comunidades relacionadas con problemas medioambientales (Cerro de San Pedro, 2009), personas con síndrome de Down (Kamikaces de la imagen, 2011), mujeres que han sido víctimas de violencia de género (Enfocadas, 2013), comunidades de Nepal (Pachadi Nepal Project, 2013), niños y niñas de Nicaragua (Niños y Niñas detrás de las cámaras, 2006), jóvenes reclusos en el reformatorio de Zaragoza (2010), ex reclusos (Fotografía desde el Socavón, 2011-2012), mujeres del barrio de Nazaret en Valencia (Nosotras hacemos barrio, Mujeres de Nazaret, 2012-2014). 
lamos en el campo de la creatividad, la imagen, la investigación-acción participativa, la educación artística, la facilitación de grupos, el yoga, la danza y el movimiento expresivo... ¡y seguimos! Con PNL ${ }^{11}$, igualdad de género, investigación en performance, pedagogía, movimiento expresivo... entusiasmadas por aprender, aplicar, empoderar y compartir. (http://www.lascientovolando.org/ Consultado: 3 marzo 2016.)

Las dos fotógrafas de este colectivo se encuentran en búsqueda constante de diferentes estrategias para conseguir sus objetivos. No se quedan ni mucho menos solamente en la fotografía, exploran a través de otras técnicas artísticas y siempre que pueden colaboran con otros profesionales para hacer sus proyectos mucho más completos.

Por ahora el proyecto que llevan a cabo se llama Fotografiar desde dentro, y consiste en una serie de talleres de fotografía y estimulación sensorial, financiados por diferentes clientes, "diseñados para personas con discapacidades visuales, auditivas o intelectuales donde investigamos sobre la percepción sensorial aplicada a la creación fotográfica" (Almudena Caso, diario de campo, 13 noviembre 2014). Tal como explicaba Eva Sala en la entrevista:

Empecé a hacer cosas de teatro sensorial, y descubrí que tenía olfato. Participé en actividades de teatro sensorial y me di cuenta de lo visual que soy, o lo veo o no siento nada, y los fotógrafos somos así. Yo pensé que esto se puede trabajar muy bien con la foto, experimentar con otros sentidos que nos pueden ayudar para la fotografía. (Diario de campo, 20 agosto 2014).

Son talleres de corta duración (uno o varios fines de semana) y en ellos trabajan con grupos muy heterogéneos en cuanto a género, edad, capacidades físicas y/o psíquicas...también colaboran con otros profesionales que complementan perfectamente sus objetivos - por ejemplo en movimiento expresivo, Proceso Corporal Integrativo (PCI) - y se integran para que los talleres supongan una experiencia sensorial significativa para las personas que participan en ellos.

\subsubsection{Photographic Social Vision}

La Fundación Photographic Social Vision (PSV) es una entidad sin ánimo de lucro que gestiona desde el año 2001 la creación, producción y difusión de reportajes documentales y fotoperiodísticos con los objetivos de informar y sensibilizar a la sociedad sobre temáticas poco conocidas, así como fomentar el interés público por la fotografía documental. Su propuesta centrada en la fotografía participativa se denomina "Punt de Vista", que describen de la siguiente manera en su página web:

"Punt de vista" es la apuesta de Photographic Social Vision por posicionar la fotografía como una herramienta de educación, expresión e integración. Buscamos documentar realidades sociales a través de la mirada de quien las vive: colectivos que no siempre tienen acceso a la fotografía o al lenguaje fotográfico. Utilizamos la fotografía como herramienta para traducir y representar la realidad [...] El vínculo que se crea entre una imagen y quién la hace es único, la foto no es más que el resultado de nuestro propio

11 Programación Neurolingüística. 
punto de vista. El principal objetivo del taller es dar las herramientas necesarias a sus participantes para fomentar el desarrollo de una mirada personal hacia el entorno próximo a través de la fotografía, entendiendo los procesos y herramientas que vinculan la imagen con nuestra mirada. Aprender a mirar entendido como una actitud, un compromiso personal y un descubrimiento; despertando las propias inquietudes, la curiosidad y la intención de dicha mirada. (http://photographicsocialvision.org/puntdevista/ Consultado: 6 abril 2016).

Entrevisté a Alice Monteil — que lleva unos 10 años relacionada con la entidad-y me me comentó los proyectos participativos de la fundación, haciendo hincapié en los que ella ha participado directamente:

- Aprender a mirar a los 70 (2004-2005). Proyecto realizado en el Casal de Gent Gran de Gràcia durante 7 meses. Lo gestiona y lleva adelante Caro García, que fue la creadora del proyecto Punt de Vista y la persona que coordinó durante años los proyectos participativos de la fundación. En este proyecto se trabajó con 16 personas mayores de 70 años y como explican en la web se fomentaron sobre todo dinámicas prácticas, poniendo "deberes" a los participantes entre una semana y otra.

- Proyecto Hombre (2006). Colaboración con la Fundación de un fin de semana dentro de actividades que ésta organiza para sus voluntarios en las que 12 personas trabajaron con sus propias imágenes y también las imágenes de fotógrafos profesionales, realizando posteriormente debates y reflexiones.

- Resistirse a Olvidar. Taller de fotografía participativa con enfermos de Alzheimer y sus familiares (2008). Proyecto realizado por el fotógrafo Jordi Oliver en el que los objetivos principales eran acercar una nueva herramienta de comunicación y expresión a un colectivo marginado, desarrollar un método terapéutico del uso de la fotografía para estos enfermos y crear un material fotográfico útil para este colectivo.

- Paisajes personales (2010)/ / Punt de Vista: Besòs (2014). Estos dos talleres fueron un encargo de La Caixa para trabajar con adolescentes inmigrantes. Fueron coordinados por la entrevistada, Alice Montiel, y llevados a cabo por Caro García y Mireia Plans con el soporte de la arteterapeuta Maite Mena. Algo que explicó Montiel del primero de los talleres es que uno de los objetivos, la cohesión y la integración, fue el detonante de revisión de este proyecto, ya que los participantes demandaron al final del taller que se abriera a personas con otra relación con el lugar, teniendo en cuenta su deseo y dificultad de contacto con los jóvenes y las jóvenes de la ciudad. A raíz de esto surgió una reflexión positiva para siguientes talleres. Por ello, el segundo taller, realizado en el barrio de Besós, se planteó desde este objetivo: unir grupos de un mismo barrio con diferentes orígenes, grupos de jóvenes con edades parecidas pero que no se relacionan entre sí. Este es el último proyecto realizado desde la Fundación y les ha llevado a abrir el taller a la ciudad, captando jóvenes con perfiles muy distintos que comparten un interés: la fotografía como herramienta de expresión.

- Amb veu pròpia (2010)/ Cadaunería (2012)/ Gente genial (2015). Estos tres talleres forman parte de un mismo proyecto realizado en la Llar de Sant Martí (Barcelona), espacio de convivencia para personas con discapacidades 
derivadas de enfermedades mentales. Amb veu pròpia es la primera fase del proyecto, realizado por la fotógrafa Patricia Esteve, a quién pude entrevistar. Lo primero que destacó de este proyecto es la colaboración con un psicólogo externo al centro, y remarcó que es esencial en un proyecto con personas con enfermedades mentales, para poder actuar con la mayor responsabilidad y sabiendo lo que se hace cuando se propone una dinámica en torno a la imagen fotográfica. Reproduzco aquí el relato de Patricia sobre lo que consideraba más importante de este proyecto:

Me di cuenta que las salidas eran muy importantes, porque salíamos, había interacción con fotografía, estaban en la sociedad, y eso es la parte buena. Para mí ese era el objetivo máximo, hay muchos talleres de este tipo que quieren luego ayudar para la reinserción, yo no voy tan allá, porque eso es otra historia, yo creo que es bueno para ellos para vivir el momento, para disfrutar de algo que no han hecho nunca y tienen la oportunidad de hacerlo (diario de campo, 11/10/2014).

Una segunda fase del proyecto se realizó el año 2012, y las docentes fueron Alice Monteil y Mireia Plans, con la colaboración de una psicóloga, Begoña Bernal. Durante todo el taller asistieron un grupo fijo de 7 personas. Mireia Plans me explicó en la entrevista que el colectivo funciona muy bien con la fotografía, ya que a través de ella pudieron trabajar tanto la relación con los demás (con las salidas y dinámicas conjuntas) como con uno mismo (cada participante desarrollaba un diario con sus imágenes). Según Plans "lo que queríamos era acompañarlos en que puedan reconocerse como seres únicos, ver su especificidad y reconocerla en la imagen y apoyarla desde cada uno, esa cadaunería" 12 . Montiel también valora la calidez humana, la sensibilidad, el humor y la falta de filtros y clichés que normalmente tenemos, aunque reconoce que también hay que saber descodificar ciertos mensajes.

La última fase del proyecto se ha denominado "Gente Genial" (2015), y ha finalizado recientemente, por lo que no he podido entrevistar a sus coordinadoras sobre el mismo ${ }^{13}$. Tal como escriben en su página web:

Esta vez hemos trabajado durante cuatro meses el vínculo de los fotógrafos amateurs con la gente de su barrio, el de Sant Martí. Considerando a menudo la ciudad como un lugar impersonal que hace especialmente invisibles a quienes no tienen un rol activo en sus calles, el proyecto buscó generar nuevos espacios y tiempos de encuentro (http://creacionweb.eu/psv2/webwp/pt_educacion/gente-genial/ Consultado: 6 abril 2016).

\subsubsection{Piel de Foto}

Piel de Foto nace el 2009 para explorar con libertad e independencia un fotoperiodismo que en los medios convencionales anunciaba su muerte a pesar de estar en pleno boom de la fotografía documental. Detectaron un vacío dentro del panorama fotográfico nacional. No había ninguna revista de corte documental o fotoperiodístico,

12 En el vídeo documental del proyecto se explica el porqué de este nombre.

13 En la siguiente dirección puede verse un corto documental que explica el proceso del proyecto: https://www. youtube.com/watch?v=JxXDQcNE-_c (Consultado: 6 abril 2016). 
con reportaje puro y con espacio para emergentes con talento. Y gracias al espíritu irreverente que les caracteriza, decidieron crear un periódico que, además, debía ser gratuito (http://pieldefoto.eu/. Consultado: 21 marzo 2016)

Sobre este colectivo entrevisté a Adriana Nicosia, una de sus fundadoras. En esta entrevista explicó que aunque por el momento solo hayan realizado una primera experiencia en talleres de fotografía participativa, en Piel de Foto siempre han buscado llevar la imagen documental allí donde la gente pueda verla. No solo editando una revista gratuita, sino también sacando imágenes físicas a la calle, haciendo impresiones de diferentes dimensiones para colgar en paredes y edificios, colocando una exposición en la calle, y de manera improvisada, en un importante festival de fotorreportaje, entre otras experiencias. Como expuso Adriana, "la foto a la calle tiene que llegar".

Los Espacios Re-Conocidos. Fotografía Participativa en Viladecans (2013-2014) es un proyecto de fotografía participativa desarrollado en el barrio de Ponent de Viladecans. A partir de la fotografía propone una reflexión en torno a la(s) identidad(es) que se produce(n) mediante los espacios habitados, sean éstos públicos o privados. Ha sido llevado a cabo por Adriana, que ha estudiado comunicación y fotografía, Monia Braghini que es mediadora intercultural y Mónica Lou, fotógrafa profesional.

En este proyecto entran en juego la memoria histórica del barrio y el presente de los habitantes/participantes que, tras las reflexiones generadas en el taller, se plasman en imágenes. De forma singular, pero también colectiva, se decide cuáles son las formas y los medios de socializar y visibilizar las fotografías realizadas, de manera que éstas puedan seguir generando preguntas en las personas que tengan la posibilidad de mirarlas. Para que las reflexiones generadas en este espacio, y sobre todo las imágenes, tengan una repercusión justamente en el contexto de origen, la mayoría de las fotografías realizadas a lo largo de este taller encuentran su lugar de exposición en las mismas calles, edificios y plazas que retratan, gracias a una intervención en el espacio público durante las fiestas del barrio de Ponent (Tarragona).

Para los participantes en el proyecto, la fotografía constituye un medio de expresión y empoderamiento a través del cual profundizar en el conocimiento que cada uno tiene de sí mismo y del entorno que habita, incorporando un nuevo lenguaje para narrar su cotidianidad.

Durante los 5 meses que duró el taller, y una vez a la semana, se trabajaron aspectos técnicos y teóricos de la fotografía. Además se creó un entorno íntimo y respetuoso donde se trataron temas no directamente ligados a la fotografía. También invitaron a profesionales que acudieran a los talleres y pudieran explicar sus proyectos y estrategias para crear debate dentro del grupo. Éstos fueron un experimentado fotoreportero (Ángel García), un filósofo especializado en movimientos obreros (Raúl Olivencia del Pino), y un arquitecto que trabaja el tema del espacio público (David Bravo). Según Adriana, esto enriqueció mucho al grupo e hizo más completo todo el proceso. Se realizaron además cuatro montajes de fotografía y texto, surgidos de las reflexiones durante el taller y de los intereses de sus participantes. Uno de ellos sobre la historia del Poblat Roca, otro sobre la huelga en la fábrica Roca (1976-1977) ${ }^{14}$, otra sobre la mercería que tenía una de las participantes y que había sido un lugar de encuentro en el barrio durante muchos años, y otra sobre el mismo grupo y el lugar físico donde se realizaban los encuentros, la ex escuela Dr. Fleming.

14 Una de las más largas de la historia de España, en la cual participó el padre de una de las participantes. 
Algo que desde el colectivo se cuida mucho es la difusión de las imágenes realizadas durante el taller. Por una parte, $\mathrm{y}$ aprovechando las fiestas patronales, colgaron del edificio en el que viven dos de las participantes unas lonas que reproducían retratos de sus habitantes. La entrevistada destacó el trabajo de intermediación de una de ellas para poder entablar relación con los vecinos y hacerles las fotos. También se preparó una exposición en la calle para que la gente viera las fotos que habían hecho los participantes. Aunque el taller acabó en febrero, la exposición final se hizo en junio para poder coincidir con fechas festivas en el barrio y multiplicar así las posibilidades de que las personas vieran las fotos.

Una reflexión interesante, y que además se repite en varias entrevistas, es que la entrevistada plantea para un futuro la colaboración con la figura de un profesional de la Psicología en el trabajo de fotografía participativa en colectivos de mujeres, buscando la honradez y el apoyo si se plantean determinadas cuestiones para las que ella reconoce no está preparada a responder. Este tipo de reflexiones han surgido a través de la práctica, y creo que es importante verbalizarlas y compartirlas.

\subsection{Recapitulación de las principales conclusiones extraídas de la investigación}

En este apartado voy a enumerar aquellas conclusiones más significativas extraídas del trabajo de campo.

La fotografía es un medio muy poderoso de comunicación social, denuncia y desarrollo personal que se puede trabajar de manera colectiva en proyectos sociales.

Todo lo que sea una visión diferente a lo que vemos con los ojos, ya puede servir para que alguien se plantee cosas. Desde su propia realidad, buscamos que el niño pudiera teniendo una cámara en la mano fijarse un poco en lo que quería fotografiar, no sé si los que no tienen acceso a cámara se lo han planteado (allí en el Sáhara no había apenas cámaras). Cómo un niño cuando se plantea que quiere hacer la foto, qué quiere hacer, pues un poco que se vea inmerso en su realidad, en su entorno, gracias a utilizar una cámara. Que la cámara les sirve para fotografiar ese entorno y luego observarlo (Aitor García, colectivo ContraPunto Social ${ }^{15}$, diario de campo: 30 septiembre 2014).

Si la fotografía tiene este poder de hablar de determinadas cosas está muy bien exponerlo en grandes dimensiones en una calle y que la gente lo pueda ver, y que al menos te plantee preguntas (Adriana Nicosia, diario de campo: 16 noviembre 2014).

Comienzo por lo más básico, pero creo que es esencial plantearnos una y otra vez en cualquier disciplina social por qué y para qué la fotografía. Todos los entrevistados han coincidido en que una de las bases de todos los proyectos de fotografía participativa es proporcionar el acceso a las cámaras y a la expresión a través de la fotografía a personas o colectivos que lo no tienen normalmente. También me refiero aquí a personas que sí utilizan sus cámaras (incluyendo las del móvil) pero que no conocen las bases del lenguaje visual que pueda facilitarles conseguir llegar a transmitir un mensaje.

En cada colectivo encontramos diferentes orientaciones y motivaciones así como métodos también diversos, pero todos ellos tienen en común el convencimiento de

15 También pude hablar con dos integrantes de este colectivo, pero he decidido no incluirlo entre los cuatro que 
que la fotografía sirve para desterrar prejuicios y clichés, acercar posiciones entre las personas, facilitar la comunicación, denunciar situaciones injustas. Normalmente en los proyectos de fotografía participativa se trabaja con colectivos en riesgo de exclusión social o que viven en entornos en los que son marginados o se vulneran sus derechos. Por ello se busca que estas personas encuentren una herramienta de expresión personal que les permita dar a conocer su manera de vivir, su punto de vista sobre diferentes temas y que también pueda trabajar su propio desarrollo personal. También hay un objetivo claro de denuncia, como es el caso de los proyectos que se desarrollan en cárceles y que están siendo llevados a cabo por el colectivo Ruido Photo. O el proyecto del colectivo punk en Cuba, que busca desterrar clichés asociados al mismo.

En relación a la investigación social cualitativa que trabaja con y sobre la fotografía, ya sea como metodología y/o objeto de estudio, debemos plantearnos para qué y por qué tiene una presencia importante durante la investigación. Utilizándola en la etnografía introducimos un elemento adicional, y por ello debemos plantearnos cómo trataremos con ella. Basándome en mi propia experiencia etnográfica y en otros trabajos de investigación como los enumerados en la primera parte de este artículo, puedo decir que la fotografía puede suponer un canal de comunicación esencial, yendo más allá de un mero uso ilustrativo y tomando la capacidad de la práctica fotográfica para implicar a personas de diferentes edades, sexos, procedencias, creencias, etc... Esto, poniendo la cámara en manos de los informantes, tal y como hacen los proyectos de fotografía participativa arriba descritos.

Los objetivos de los proyectos de fotografia participativa deben relacionarse con las características del colectivo con que se va a trabajar y con la duración y recursos del proyecto.

Se expresa una necesidad de conocer a las personas con las que se va a trabajar y el entorno en que viven antes de realizar los talleres de fotografía participativa. Debe haber un conocimiento previo del entorno en el que se trabaja, porque si no surgirán desde el principio una serie de problemas que quizá no se puedan resolver. Un ejemplo lo puso Eva Sala cuando trató acerca de un proyecto con mujeres maltratadas $^{16}$, en el que advertía del error de trabajar con este colectivo sin estar informada de los procesos terapéuticos que han seguido, de las cuestiones legales, es decir, de hechos fundamentales para estas personas. Según comentaba la entrevistada sobre el proyecto Enfocadas, gran cantidad del tiempo invertido en este proyecto lo utilizó para "estar ahí, escuchar, soportar e intentar tener empatía con esas mujeres y callarme la boca, punto". En este proyecto trabajaba en igualdad de condiciones con una terapeuta.

En relación a esto hay que remarcar que según sean los objetivos, los proyectos se basarán más en el proceso o en el resultado. En realidad, en todos los proyectos se valoran ambas cuestiones, pero se hará hincapié en un aspecto u otro. Esto depende en parte claramente de la duración de los talleres. Cuanto más corto (podemos estar hablando de proyectos de máximo un mes), más se valora el proceso, ya que no existe tiempo para poder trabajar en profundidad el lenguaje visual y sus diferentes posibilidades, para asimilar los conceptos. Cuando hablamos de proyectos a largo plazo (aproximadamente con una duración de más de 12 sesiones) encontramos unos

16 Este proyecto se denomina Enfocadas, y fue llevado a cabo por la fotógrafa Eva Sala y la terapeuta Marcela Lockett. Eva Sala es una de las componentes del colectivo Las Cientovolando. 
resultados técnicamente más cuidados en los que puede verse que la preparación de los participantes es mucho mayor y ha sido posible trabajar con diferentes tipos de cámaras y técnicas. En este sentido, creo que es importante reflexionar acerca de los objetivos que nos planteamos.

En el caso de Las Cientovolando y los trabajos de Fotografiar desde Dentro encontramos proyectos de fotografía sensorial que incluyen otras técnicas artísticas además de la fotografía y que buscan que los participantes vivan una experiencia en torno a los sentidos y la expresividad. Hay que decir que son proyectos de corta duración (dos días, una semana) que se centran mucho en este proceso. En el caso de otros proyectos como los desarrollados en cárceles por Ruido Photo encontramos un material fotográfico mucho más profesional que se ha desarrollado a través del tiempo, poco a poco y con una estancia prolongada dentro de las prisiones. También puede pasar cuando trabajamos con colectivos que ya han tenido contacto con la cámara o con otras expresiones artísticas y la transmisión de conocimientos es entonces mucho más rápida y eficaz desde el principio. Por ejemplo, Eva Sala me habló sobre el proyecto Kamikaces de la imagen ${ }^{17}$ y la idoneidad del medio fotográfico con este colectivo, ya que según le dijo una psicóloga, las personas con síndrome de Down recuerdan más lo que ven que lo que escuchan, así que es una técnica artística ideal para muchos de ellos. Josu Trueba sobre el proyecto Cuidado que muerden, explicado anteriormente, me decía que se notaba en los resultados la formación artística previa. Añadía: "Está muy bien el proceso, es muy gratificante y cómo va evolucionando y todo... pero necesitamos un resultado" (diario de campo, 23/11/2014)

Finalmente, en algunas entrevistas hemos tratado acerca del peligro de marcar objetivos demasiado ambiciosos, dirigidos a cambiar significativamente la vida de las personas con las que se trabaja durante un periodo de tiempo. Por ejemplo, Adriana Nicosia (Piel De Foto) en relación al proyecto realizado en Viladecans, explicaba que entre sus objetivos no estaba solucionar conflictos entre diferentes colectivos del barrio:

Nosotras no hemos tocado estos conflictos ni los hemos resuelto [...] nos hemos dado cuenta que no era el lugar para hacerlo, no era el lugar para llevarlos a la convivencia pacífica. No nos íbamos a meter en términos de convivencia, mi objetivo no era este. Nosotras estamos aquí para fotografiar, para aprender a fotografiar, pero cada cual que haga lo que quiera (diario de campo, 16/11/2014).

Patricia Esteve explicaba que los objetivos de su proyecto Amb veu pròpia, consensuados con un fotógrafo, estaban relacionados con fomentar la sociabilidad, la asunción de responsabilidades, entre otros: "Estas pequeñas cosas creo que ayudan más que no buscar grandes cosas para ellos, ya tienen demasiada presión en sus vidas".

Almudena Caso hizo una interesante reflexión sobre los objetivos de un proyecto de fotografía participativa:

17 Kamikaces de la imagen (2011) es un proyecto que Eva Sala comienza en 2009, cuando realiza una jornada con un grupo de jóvenes con síndrome de Down en Toledo. Durante este día se da cuenta de las potencialidades que tiene trabajar con este colectivo, y lo idóneo del medio fotográfico para plantear un proyecto. Después de negociaciones con Down España y búsqueda de financiación, realiza un proyecto durante 1 año con asociaciones vinculadas a Down España en tres ciudades: la Asociación Andi Sabadell, Down Córdoba y Down Toledo. 
Para mí es interesante que siempre quede claro por qué estoy ahí y cuál es mi intención. Que siempre es visibilizar el cotidiano, la realidad de ese colectivo y que ellos mejor que nadie pueden hablar de ello. Esto es importante (diario de campo, 13 noviembre 2014).

Finalmente, los fotógrafos de esta investigación lo que quieren es acercar y facilitar una experiencia con la fotografía a las personas implicadas en un proyecto, para que expresen su punto de vista. El alcance que estos resultados tenga dependerá del devenir del proyecto, y de los objetivos marcados. Se trata al fin y al cabo, como reflexionaba una de las fotógrafas, de aportar más verdad a un proyecto de fotografía documental.

\section{Búsqueda de sinergias con otros profesionales}

A partir del trabajo de campo he constatado que existe una clara tendencia a realizar proyectos de fotografía participativa en los que colaboran diferentes profesionales en algunas o en todas sus etapas. En algunos de los proyectos descritos se ha trabajado de manera coordinada con psicoterapeutas, educadores sociales, arquitectos, bailarinas, poetisas, actores...dando gran importancia al trabajo que han realizado y reconociendo que sin ellos no hubiera sido posible. Sobre todo se destaca este aspecto en aquellos espacios en los que las personas pasan o han pasado por procesos terapéuticos (Enfocadas, Amb veu propia, Resistirse a olvidar, Cadaunería). También hay proyectos como Fotografiar desde Dentro que experimentan con profesionales de otras disciplinas artísticas, como el teatro, la escultura o la expresión corporal. En el trabajo con niños y adolescentes se valora muy positivamente la colaboración con profesionales de la educación social, ya que los fotógrafos, en la mayoría de los casos, no cuentan con estrategias para sacar adelante las dinámicas planteadas, y el trabajo en conjunto con estos profesionales hace que el proyecto tenga muchas más posibilidades de tener éxito y cumplir con los objetivos planteados.

Un aspecto importante que se ha destacado en varias entrevistas es que los profesionales con quienes se trabaja sean independientes de los entornos institucionalizados en que se lleva a cabo los proyectos, que se les pueda contratar para realizar los talleres. Esto sirve para evitar confusiones entre los participantes y tener libertad para actuar, eso sí, teniendo en cuenta las normas de los lugares en que se desarrollan los proyectos - en ocasiones pueden negociarse, pero normalmente hay que ceñirse a ellas-.

Ninguno de los proyectos estudiados han incluido a un profesional de la Antropología para desarrollar una investigación social, de ahí que me parezca necesario y muy interesante abrir la reflexión sobre qué podemos hacer como antropólogos en proyectos de este tipo.

\section{Dificultades de financiación}

La financiación ha aparecido en todas las entrevistas como la mayor dificultad a la hora de llevar adelante un proyecto. Por eso, no es nada raro hacer los proyectos " $a$ pulmón" (en palabras de los entrevistados), es decir, sin ningún tipo de financiación o sabiendo que te han concedido un importe, pero que pueden pasar meses hasta que lo recibas. 
Existe solamente una línea de financiación privada ${ }^{18}$ que se acerca a lo que hacen estos colectivos con la fotografía participativa, y casi todos los entrevistados la han recibido en algún momento. A nivel de ayudas desde la administración pública apenas aparecen líneas adecuadas a sus objetivos. Aparece también como posibilidades el crowdfunding e incluso la búsqueda de donaciones privadas ${ }^{19}$. Buscar financiación se lleva una gran parte del tiempo de un proyecto. Pau Coll comenta:

En España no tienes posibilidad de recaudar fondos, que no aquí que no es una prioridad. En general en cooperación, en el arte y tal estamos en un lugar horrible. Y dentro de este lugar horrible, la fotografía es la hermana más ninguneada, y dentro la fotografía documental o social está en lo más más bajo. Por eso existen tan pocas intervenciones (diario de campo, 20 de noviembre de 2014).

La falta de financiación afecta al tiempo que se puede trabajar con el colectivo, a las posibles colaboraciones, al material, a la difusión...eso sí, siempre se encuentran maneras de acortar los gastos porque además de ser muy pocas las líneas de financiación que encuentran los fotógrafos para realizar sus proyectos, los importes suelen estar también muy ajustados.

\section{El futuro de la fotografía participativa}

Es evidente que nos encontramos en un claro auge de esta metodología dentro del mundo de la fotografía y también desde otros ámbitos profesionales. En los últimos años se están multiplicando los proyectos (a pesar de las dificultades) y hay mucho más conocimiento de lo que unos y otros están haciendo.

Una cuestión que se plantea es la de homogeneizar la metodología, es decir, crear una serie de parámetros que debe tener todo proyecto de fotografía participativa y establecer así unas bases y unos mínimos para dedicarse a este tipo de acciones. También existiría la posibilidad entonces de institucionalizar en cierto modo la práctica, creando escuelas y difundiendo el conocimiento adquirido por los profesionales. Ya se están impartiendo clases sobre el uso de esta metodología en diferentes foros (Universidad, Escuelas de fotografía, coloquios) y parece que la tendencia es compartir las experiencias a diferentes profesionales interesados en poner en práctica proyectos de este tipo en sus áreas de trabajo.

Es positivo crear estos espacios para compartir experiencias, como también establecer parámetros mínimos en los proyectos de fotografía participativa. Algunos de los entrevistados demandan un código deontológico en el que se establezcan unas bases, por ejemplo en lo que se refiere a la formulación de objetivos, la difusión de los resultados de los proyectos, la elección del colectivo, el conocimiento del terreno en el que vas a trabajar, el compromiso con los participantes, la interdisciplinariedad... temas que he intentado tratar en estas páginas y que quedan para futuros debates que espero cuenten con muchas y diferentes voces.

\footnotetext{
18 Me refiero a las ayuda de la Obra Social de La Caixa para proyectos artísticos de transformación social.

19 En varios de estos proyectos se ha trabajado con cámaras donadas (por ejemplo, en Niños y Niñas detrás de las cámaras). $\mathrm{O}$ en el caso de Anna Bosch, que realizó una rifa para sortear su cámara de fotos réflex para conseguir dinero para el proyecto Las flores del rancho.
} 


\subsection{Propuesta de integración de la investigación social en proyectos de fotografía participativa}

Por último quisiera exponer brevemente una serie de cuestiones que podemos aportar los profesionales de la Antropología en un proyecto de fotografía participativa realizado conjuntamente con fotógrafos profesionales. La cuestión es colaborar durante todo el proceso, desde el inicio con la elección de los colectivos con los que trabajar hasta las etapas finales, que implican un trabajo de edición fotográfica conjunta y difusión de los resultados. Se trata, entonces, de buscar una colaboración en igualdad de condiciones con todos los actores implicados en el proyecto. Propongo entonces estas líneas generales de trabajo sobre las que experimentar y profundizar en futuros proyectos.

1. Obtener una respuesta constante y mantener una evaluación al día de los talleres, realizando entrevistas en profundidad a todos los participantes acerca de sus vivencias en los mismos y llevando a cabo observación participante con el posterior registro en el cuaderno de campo.

2. Incidir y dar la importancia necesaria al texto en conjunción con las imágenes, a partir de transcripciones de nuestras observaciones y de las propias palabras de los participantes. Hacer propuestas acerca de esta importante conjunción texto/foto para luego consensuar en el grupo las diferentes posibilidades y el resultado final.

3. Trabajar con los participantes tanto con las imágenes de sus vidas (álbum familiar, redes sociales...) como con las que van produciendo durante los talleres, conociendo sus puntos de vista y dejando que sean ellos y ellas quienes expliquen aquello que podemos ver. Incidir en la fotografía como parte importante de la historia personal.

4. Compartir en todo momento los resultados y los análisis hechos acerca de los talleres, para crear así un clima de debate sobre los temas más significativos que vayan surgiendo durante los mismos.

5. Detectar aquellos temas que interesa tratar a los participantes del taller y propiciar dinámicas sobre éstos a través de la fotografía. Paralelamente, investigar acerca de estos temas para poder plantear actividades relacionadas con los más significativos, o buscar colaboraciones con profesionales que trabajan dichas materias.

6. Redactar una memoria final de los talleres analizando el proceso y el material producido durante los mismos.

7. Apoyar en la difusión de los resultados en ámbito académico y la búsqueda de colaboraciones de otros investigadores en futuros proyectos. En este sentido, se debería potenciar que en los programas académicos de Antropología puedan incluirse el aprendizaje de este tipo de metodologías. 


\section{Referencias bibliográficas}

Asch, Timothy (1995). «La colaboración en la realización de documentales etnográficos: una visión personal», en E. Ardévol y L. Pérez Tolón, (Eds.). Imagen y cultura. Perspectivas del cine etnográfico, Biblioteca de Etnología, 3. Diputación provincial de Granada, 255299.

Bayona, Eugenia (2001). Las camaristas Sbeik. Mujeres indigenas fotógrafas en San Cristóbal de las Casas, Chiapas. Tesis de maestría, Centro de investigaciones y Estudios Superiores en Antropología Social, Ciesas Sureste, San Cristóbal de las Casas, México.

Edwards, Elisabeth (1999). "Beyond the boundary: a consideration of the expressive in photography and anthropology" in: Banks, Marcus \& Morphy, Howard (Ed.). Visual Anthropology Rethinking. Yale University Press London: 53-79.

González, Paula (2011a). "La fotografía participativa como medio de investigación y análisis social. Nota etnográfica sobre la experiencia con un grupo de adolescentes en el ámbito educativo", Revista Quaderns-e del Institut Català d'Antropologia, 16 (1): 147-158. http://www.antropologia.cat/quaderns-e-176.

- 2011b. "Tú mira la foto pero no se la enseñes a nadie” Análisis de la práctica, los discursos y las representaciones de niños y adolescentes en el contexto de talleres de fotografía participativa. Dos estudios de caso. Tesis doctoral, Universitat Rovira i Virgili, Tarragona. http://www.tdx.cat/handle/10803/51883

- 2014. "Apuntes sobre la fotografía como metodología participativa en la etnografía", Arxiu D’Etnografia De Catalunya, número 14: 33-53.

Gimeno, Juan Carlos (2008). “Antropología(s). de orientación pública: Asomarse unos centímetros más allá del borde, ahí donde la perspectiva se amplía ligeramente”. En Antropología de orientación pública: visibilización y compromiso de la antropología. XII Congreso de Antropología de la Federación de Asociaciones de Antropología del Estado Español (FAAEE). Pilar Monreal, Pablo Palenzuela y Mercedes Jabardo (eds). San Sebastián: Ankulegi, págs. 247-275.

Grau, Jorge (2005). "Los límites de lo etnográfico son los límites de la imaginación” El legado fílmico de Jean Rouch. AIBR. Revista de Antropología Iberoamericana, 41: 1-20.

Kolb, Bettina (2008). "Involving, Sharing, Analysing-Potential of the Participatory Photo Interview”, Forum: Qualitative Social Research. Volume 9, No. 3, Art. 14.

Lutter, Wendy (2010). "A camera is a big responsibility": a lens for analyzing children's visual voices", Visual Studies, 25, 3: 224-237.

Mizen, Phil (2005). "A little "light work"? Children's images of their labour", Visual Studies, Vol. 20, 2: 124-139.

Mizen, Phil; Ofocosu-Kusi, Yaw (2010). "Unofficial truths and everyday insights: understanding voice in visual research with the children of Accra's urban poor". Visual Studies, 25, 3: 255-267.

Packard, Josh (2008). “I'm gonna show you what's really out here”: the power and limitation of participatory photography visual methods. Visual Studies, 23, 1: 64-76.

Pink, Sarah (2001). Doing Visual Ethnography. Gage Publications, Londres.

Rahman, Anisur; Fals Borda, Orlando (1989). "La situación actual y las perspectivas de la IAP en el mundo". En Salazar, M (Ed.). La Investigación Acción Participativa, inicios y desarrollo. Consejo de Educación de Adultos de América Latina, Universidad Nacional de Colombia, Editorial Popular, OEI, Quinto Centenario, Madrid, 215-221.

Robles, Juan (2012). "El lugar de la Antropología audiovisual: metodología participativa y espacios profesionales". Íconos. Revista de Ciencias Sociales. Num. 44, pp. 147-162. 
Rouch, Jean (1974). “The camera and Man”. En Hockings, Paul (Ed.). Principles of Visual Anthropology. Mouton de Gruyter, New York, 53-71.

San Román, Teresa (2006). “¿Acaso es evitable? El impacto de la Antropología en las relaciones e imágenes sociales". Revista de Antropología Social,15: 3 73-410.

Sharples, M.C; Davison, G.V; Rudman, Thomas and P.D. (2003). "Children as photographers: An analysis of children's photography behaviours and intentions at three age levels", Visual communication, 2 (3): 303-330.

Wang, Caroline; Burris, Mary Ann; Yue Ping, Xiang (1996). "Chinese village women as visual anthropologist: a participatory approach to reaching policymakers", Soc. Sci. Med. 42, 10: 1391-1400.

Worth, Sol; Adair, John (1972). Through Navajo Eyes. An Exploration in Film Communication and Anthropology. Indiana University Press, Sloomington and London. 